\title{
The Prospect and Analysis of Nanogenerator for Wearable Device
}

\section{Jing-Yan Yu and Li Liu*}

Beijing Institute of Fashion Technology, Beijing, China

*Corresponding Author: Li Liu, Beijing Institute of Fashion Technology, Beijing, China.

Received: June 3, 2019; Published: August 17, 2019

\begin{abstract}
With the emergence of wearable devices such as Google glasses, I Watch, Active trackers and etc, people are becoming increasingly interested in wearable device and an increasing number of electronics and functionalized components are being applied to wearable devices. Even though wearable devices do not consume too much energy, the requirement for sustainability still brings a big challenge for power supplying. In fact, the battery life of most wearable devices cannot satisfy the users' demand. On the other hand, because of the devices' characteristic of being "wearable", there is much higher demand for safety, life span, pollution and comfort in power supply components. Therefore, how to provide continuous and environmentally-friendly power supply for wearable devices becomes a popular research topic. In 2012, when the Triboelectric Nano generator (TENG) was first introduced, it drew everyone's attention because of its advantages of lightweight, safety, cleanness and sustainability. The possibility of using Nano generator technology as a self-driven power supply for wearable devices will be discussed in this paper.

Keywords: Wearable Device; Nanogenerator; Energy Conversion; Self-Energized
\end{abstract}

\section{Nanogenerator}

In today's fast developing informationalized society, the business models and technology featured with movement, timeliness and intelligence are subtly driving. And then new challenges are presented on the global energy system, the mobile energy characterized with mobile, all-weather, highly efficient supply model will define a new chapter to energy demand [1]. Many types of mobile and distributed generation technologies are rising in the modern world, and one of them is the nanogenerator (NG) based on piezoelectricity, pyroelectricity, triboelectricity and electrostatic induction [2].

The nanogenerator is a technology device which can convert mechanical energy and thermal energy into electrical energy via small physical changes. There are three typical technical paths for nanogenerator: Piezoelectric, triboelectric, and pyroelectric, in which the piezoelectric nanogenerator and triboelectric nanogenerator (TENG) can convert mechanical energy into electrical energy, and pyroelectric nanogenerator (PENG) is the converting center in which the collected thermal energy during temperature fluctuations over time would be converted into electrical energy. Piezoelectric technology and triboelectric technology are commonly used in wearable equipment technological [3].
The operating principle of the nanogenerator is to use a unique coupling voltage and Zinc Oxide nanostructure, so that the array of Zinc Oxide nanowires would be vertically assembled on the top substrate to collect current. In the "Z-shaped" electrode made of silicon material, thousands of nanowires are arranged, which extend freely and generate electrical currents that drive external mechanical vibrations to continuously generate current.

\section{Wearable device}

Wearable device means a kind of portable intelligent equipment which could be worn on the body directly or easy to be worn on the apparel and accessories. In general, Wearable Device is electronic communication gears which can be embedded into clothing. Some of wearable gears even are designed to be accessories or other types of wearable items directly [4], as shown in Figure 1-4. They play a critical role in helping users to extend their perception, monitoring users' physical state and improving users' work efficiency, at the same time wearable gears could also make users feel comfortable when people are wearing them.

In recent years, the wearable device has been one of the focuses in the Information Technology area. However, it is still unclear that what makes people accept new electric devices like wearable devices today. 


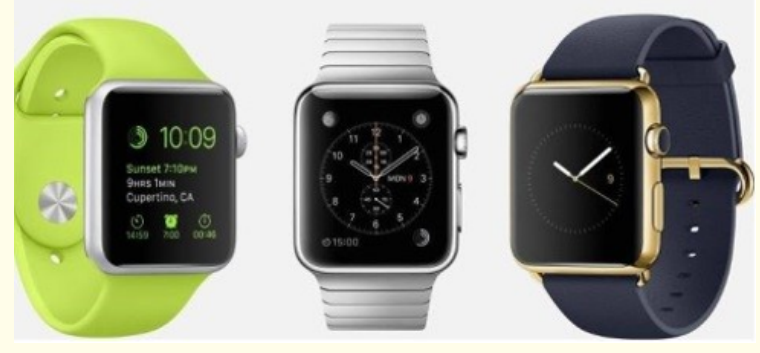

Figure1: I watch.

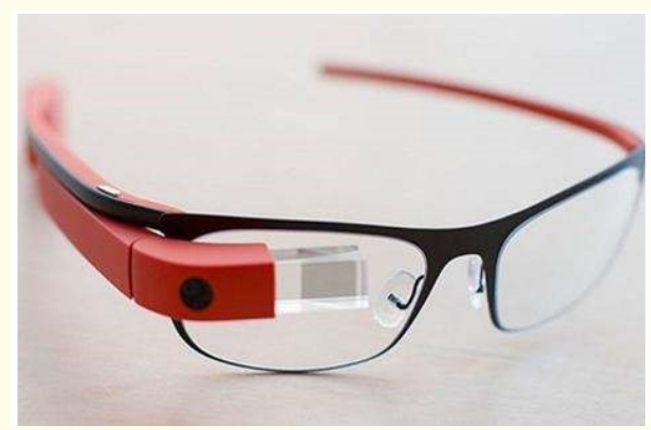

Figure 2: Google Glass.

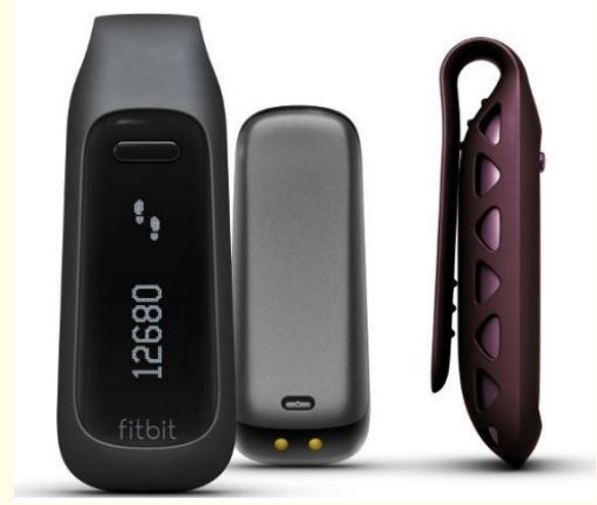

Figure 3: Fitbit.

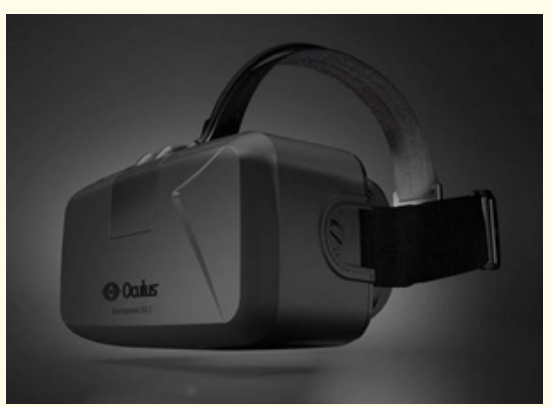

Figure 4: oculus rift.
The development prospects of wearable device

Analysis shows, macro environment is friendly to the boom of wearable devices in which users have strong interest. The oscillation of the share price of some typical companies shows us a competitive environment. And we can find it in a big start with no ensured technology, standard product and high entry barriers. All these show us a chance to be an early bird in this industry [5]. After mapping the industry chain, we can find the companies bounded by components and service suppliers, and there's also a piece of good news that the new players in this industry coming from traditional industries may make a fast move. In one word, the longer chain, the more survivors [6].

So we can find it possible for wearable device industry to be a leading industry, and the independent device will play a role in the future. As long as the wearable device industry can promote each other with the internet of things? the wearable device may finally become everything-wearable device and the data coming from wearable device will be most valuable at last [7].

\section{Development status and classification}

In recent years, the development of wearable intelligent devices have been shifting to commercial application from academic research driven by multiple factors such as industry trends, technology and user demand, as shown in Figure 5-6.

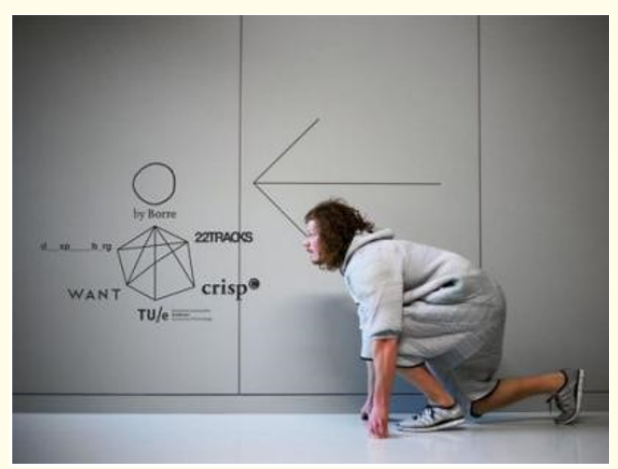

Figure 5: BB Suit Smart Piece of clothing.

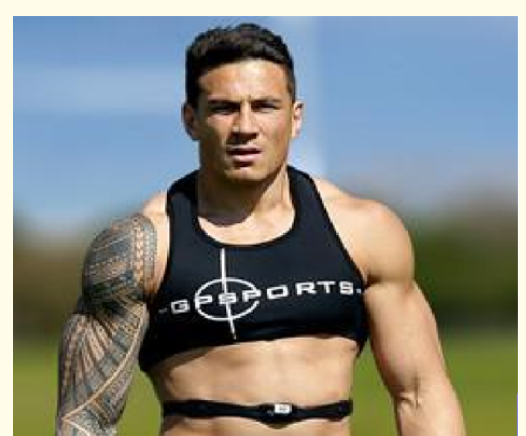

Figure 6: Gasport's Sports data vest. 
From technical view, multiple wearable gear technologies have become mature gradually. Components, operating system and the corresponding development tool platform have been rapidly developing. From the market point of view, some of transboundary internet giants get into wearable devices field and have become the main enablers for market development. Nowadays, most wearable terminals are auxiliary mobile equipment [8]. The intelligent hand ring, smart watches and smart glasses are the most common wear terminals about sports and health, attracting huge concern, as shown in table1-2. These phenomena show that consumers are no longer satisfied with the function of telephone and video for intelligent terminals but already increase their recognition and acceptance for other extended function of wearable devices.

\begin{tabular}{|l|c|c|c|c|c|}
\hline Category & Target population & Product form & interactive mode & Solve the problem & $\begin{array}{c}\text { On behalf of the } \\
\text { product }\end{array}$ \\
\hline $\begin{array}{l}\text { Fitness } \\
\text { class }\end{array}$ & $\begin{array}{c}\text { Young consumer } \\
\text { groups }\end{array}$ & $\begin{array}{c}\text { Watches, wrist } \\
\text { bands, shoes }\end{array}$ & $\begin{array}{c}\text { Graphical interface, } \\
\text { Multi channel intelligent } \\
\text { human-computer } \\
\text { interaction, Collect } \\
\text { information and data } \\
\text { through sensors }\end{array}$ & $\begin{array}{c}\text { Collect motion } \\
\text { information to } \\
\text { achieve better } \\
\text { exercise results }\end{array}$ & $\begin{array}{c}\text { Nike + Training; } \\
\text { Fitbit Force; }\end{array}$ \\
\hline $\begin{array}{l}\text { Medical } \\
\text { safety } \\
\text { category }\end{array}$ & $\begin{array}{c}\text { For the public } \\
\text { consumption, } \\
\text { infants and young } \\
\text { people as an import } \\
\text { ant target popula- } \\
\text { tion }\end{array}$ & $\begin{array}{c}\text { Watch, wrist } \\
\text { band }\end{array}$ & $\begin{array}{c}\text { Graphical interface, } \\
\text { Multi channel intelligent } \\
\text { human-computer } \\
\text { interaction, Collect } \\
\text { information and data } \\
\text { through sensors }\end{array}$ & $\begin{array}{c}\text { The collection of } \\
\text { various health indi- } \\
\text { cators, comparative } \\
\text { analysis; dangerous } \\
\text { alarm }\end{array}$ & $\begin{array}{c}\text { hand ring; Garmin } \\
\text { Vivo Fit; Samsun } \\
\text { g Gear Fit; Basis } \\
\text { Carbon Steel }\end{array}$ \\
\hline $\begin{array}{l}\text { Information } \\
\text { consultation }\end{array}$ & $\begin{array}{c}\text { For mass } \\
\text { consumption }\end{array}$ & $\begin{array}{c}\text { Glasses, } \\
\text { Watches, wrist } \\
\text { bands, clothing }\end{array}$ & $\begin{array}{c}\text { It is based on natural } \\
\text { speech interaction and } \\
\text { somatosensory } \\
\text { interaction }\end{array}$ & $\begin{array}{c}\text { Convenient, timely } \\
\text { access to } \\
\text { information; } \\
\text { entertainment }\end{array}$ & $\begin{array}{c}\text { Mote 360; Google } \\
\text { Glass; MYO }\end{array}$ \\
\hline
\end{tabular}

Table 1: Wearable device type (by function).

\begin{tabular}{|c|c|c|}
\hline Wearable terminal & Features & On behalf of the product \\
\hline $\begin{array}{l}\text { Independent terminal class smart } \\
\text { watch }\end{array}$ & $\begin{array}{l}\text { Independent cloud interaction, inde- } \\
\text { pendent call, precise positioning, data } \\
\text { services }\end{array}$ & Omate True smart, GEAk Watch. \\
\hline Mobile assistant class & $\begin{array}{l}\text { Sports health, information viewing, } \\
\text { event reminders, telephone answer- } \\
\text { ing }\end{array}$ & $\begin{array}{l}\text { Samsung, Galaxy, Gear 2, Pebble, } \\
\text { LG G Watch }\end{array}$ \\
\hline Smart bracelet & $\begin{array}{l}\text { Fitness step, sleep, monitoring, so- } \\
\text { matosensory control, vibration wake } \\
\text { up, heart rate measurement, call re- } \\
\text { minder }\end{array}$ & $\begin{array}{l}\text { MYO Wristbands, Jawbone UP, Fitbit } \\
\text { Flex, Fuel band }\end{array}$ \\
\hline Smart glasses & $\begin{array}{l}\text { GPS navigation, information consulta- } \\
\text { tion, real - time camera, virtual reality, } \\
\text { infrared medicine, synchronous dual } \\
\text { - screen }\end{array}$ & $\begin{array}{l}\text { Google Glass, Oculus Rift, DoCoMo } \\
\text { Smart glasses. }\end{array}$ \\
\hline Smart belt & $\begin{array}{l}\text { Sitting position monitoring, vibration } \\
\text { warning }\end{array}$ & Lumoback \\
\hline Smart clothing & Mobile Wi-Fi hotspots, music player & BB suit Smart piece of clothing \\
\hline Smart shoes and socks & $\begin{array}{l}\text { Motion monitoring, map navigation, } \\
\text { action guidance }\end{array}$ & No place Like Home, Smart Socks \\
\hline
\end{tabular}

Table 2: Wearable equipment type (by product type). 


\section{Existing problems}

HIS Technology points out that the scales of battery markets around the world are expected to increase more than 10 times in a short span of four years driven by the development of wearable devices in its market research report. By 2018, the battery revenue of wearable devices is expected to reach $\$ 77$ million [9].

Most wearable devices are using lithium polymer batteries now. The main reason is that this kind of battery is light and flexible for size and shape. According to survey, the income of this kind of battery has accounted for $73 \%$ of the whole earning for wearable gear battery.

However, battery is still a big bottleneck for the development of wearable devices field from the current market feedback. The main issue users complain about is the limited battery life, since the general situation of battery is that it needs recharging every several hours when devices are used continuously, which is extremely inconvenient for users and exerts negative impact on user experience. In addition, the battery will bring serious pollution to the environment and huge consumption of material resources, which does not conform to the concept of sustainable development.

Based on the problems mentioned above, the suggestion is that integrating wearable energy-harvesting and energy-storing devices into a self-sustainable or autarky client power system [10].

Google Glass costs $\$ 1,500$, and the pricing of Jawbone Can ring and Samsung Galaxy gear also reached the four-digit RMB. Such price could not do customers a favor but make ordinary public consumers discouraged. If you want to expand on a large scale exhibition market, to build civilian applications, we must reduce costs and achieve mass production. We can consider the creation of multi-level products to achieve differentiated pricing, thus not only for people with high incomes, high-profile and high-priced products for electronic products lovers, but also specifically designed products for the civilian population to create a more friendly product price, thus fully digging out consumption potential of different user groups to meet the needs of different groups of consumers [11].

Application of nano-generator in wearable equipment

The basic principle for wearable equipment of nanogenerators is the conversion of bio mechanical energy(Such as human movement, muscle stretching, blood pressure) into electricity, which is concentrated in the flexible energy storage originals to supply the electronic devices worn on the human body, as shown in Figure 7.

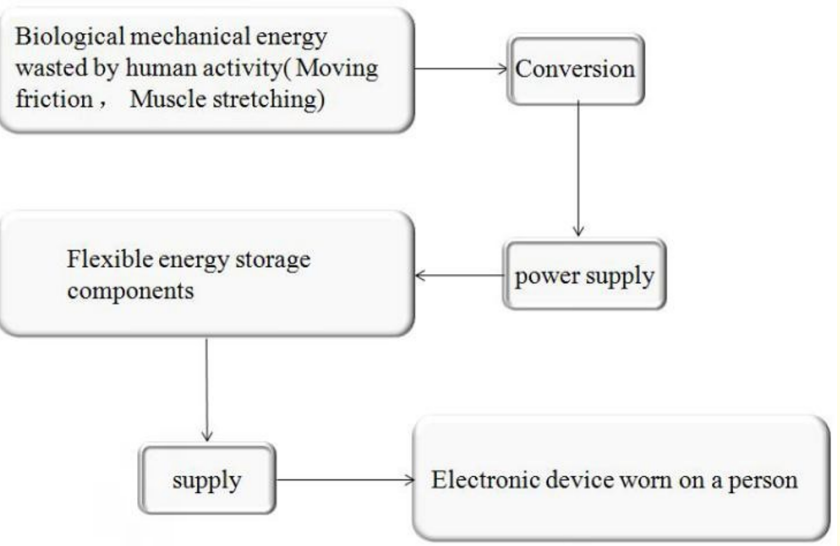

Figure 7: The structure of Nano-generator used in wearable equipment.

And based on Piezoelectricity, Pyroelectricity, Triboelectricity and electrostatic induction can collect the energy from the environment, and then drive the wireless mobile electronic device by the energy conversion to achieve energy supply. This mechanical energy is characterized by strong persistence and wide range of use, as shown in Figure 8, including walking, running, typing, touching the phone screen and even blink, breathing and other activities can become a source of energy. The ideal energy source for wearing a product is the body movement energy. T. Starner [12] reported the energy consumed by human activities in daily life, as shown in Table 3

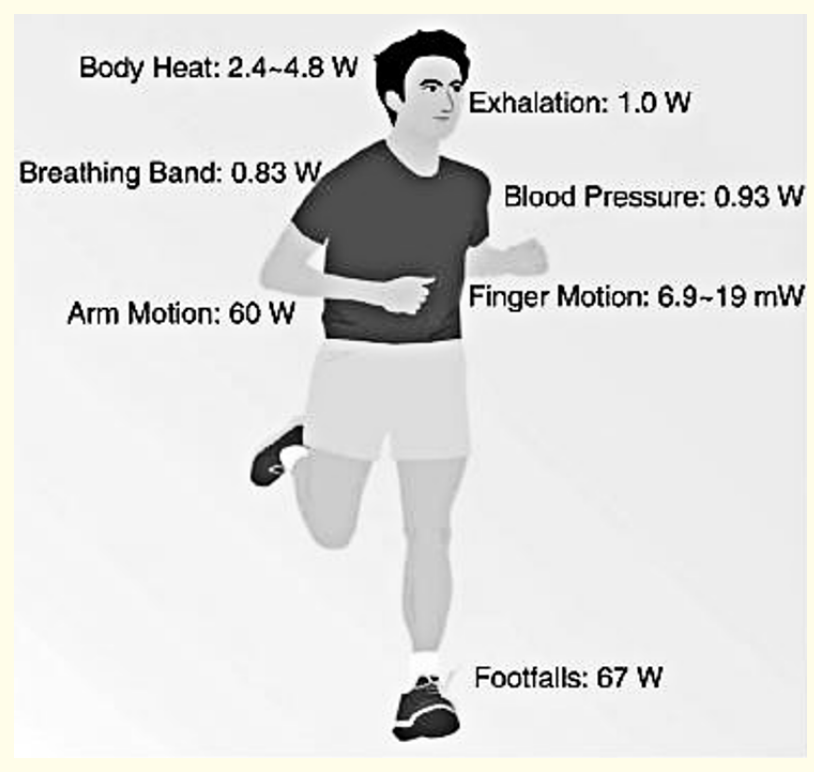

Figure 8: The energy released by the daily 


\begin{tabular}{|l|c|}
\hline \multicolumn{1}{|c|}{ Behavior } & Power $/ \mathbf{W}$ \\
\hline sit & 116 \\
\hline stand up & 128 \\
\hline take a walk & 163 \\
\hline walk & 407 \\
\hline jogging & 1048 \\
\hline run away & 1630 \\
\hline climbing & 698 \\
\hline swim & 582 \\
\hline drive & 163 \\
\hline
\end{tabular}

Table 3: Some of the energy consumed by human activities.

The physical pathways for the conversion from small-scale mechanical energy into electrical energy supply and wearable devices mainly include piezoelectric effects and triboelectric effects.

\section{Piezoelectric nanogenerator used in wearable devices}

The piezoelectric nanogenerator is an important landmark in the developmental period of nanotechnology. The piezoelectric nanogenerator converts mechanical energy to electrical energy in nanoscale, relying on the coupling of piezoelectric and semiconducting properties of nanomaterials. This approach offers a potential solution for harvesting energy from the environment for selfpowered nanotechnology [13]. This nanotechnology can not only reduce the size and weight of the electrical source, but also enlarge the range of the scavenged energy from the environment.

Invented by Professor Wang Zhonglin and the group in 2006, Piezoelectric nanogenerator is energy harvesting device which converts external kinetic energy into electrical energy. As shown in Figure 9, in most cases it is referred to the kinetic energy collection device made by piezoelectric materials in Nano-sized. The Nano-generator can integrate a variety of different forms of energy collectors, which can independently drive a variety of electronic products [14].

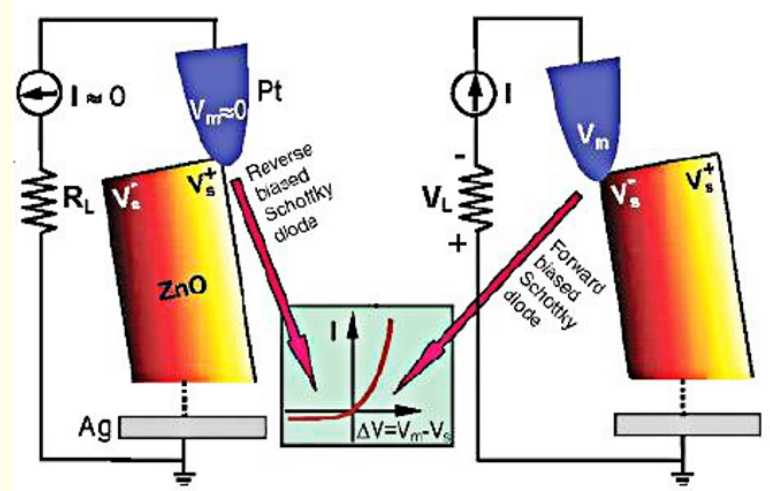

Figure 9: The working principle of piezoelectric Nanogenerator when its external force is perpendicular to its axis.

The principle of piezoelectric nanogenerator applied to wearable device

Piezoelectric Nano-generators are mainly used to device integration or fabric weaving with piezoelectric fibers. Piezoelectric fibers are used to convert the kinetic energy of the human body into electrical energy, thus being applied to the electronic device for driving the wearable device. Just like as a health management system with an intelligent wearable system, Piezoelectric Nanogenerator is also easily integrated into shoes, collecting energy from people walking which would be converted into electricity to be used. But there are a lot of problems in the energy collection system of piezoelectric Nano-generator.

The existing problems of the piezoelectric nanogenerator in wearable applications

1. Although the use of piezoelectric principles of mechanical energy into electrical energy research has been more indepth, the power of piezoelectric nanogenerator is generally at the level of $\mu \mathrm{W}$ `nW, so the efferent energy is not enough to drive wearable equipment [15].

2. The type of material with piezoelectric properties is relatively limited, resulting in its narrow range of applications; it cannot be used on a large scale in wearable equipment. The Triboelectric Nano-generator can solve this problem well.

\section{Triboelectric nanogenerator used in wearable devices}

The triboelectric nanogenerator (TENG) is a newly developed energy-harvesting technology that converts mechanical energy into electric power with a coupled effect of contact-electrification and electrostatic induction. This new type of nanogenerator was invented by Professor Dr Zhong Lin Wang of Georgia Institute of Technology in the United States for the first time; it was proved to be a simple, low-cost, stable structure, and efficient way to collect mechanical energy. As shown in Figure 10, the triboelectric nanogenerator (TENG), based on the coupling between tribe electrification and electrostatic induction, can convert mechanical energy into electrical energy which will provide a new way for the harvest and conversion of human activity. With liquid and air flow existing in the natural environment, it has a huge potential for application value in the field of new energy technology and self-powered active sensors [16].

It is critical and essentially necessary to develop the TENG extensively because TENG technology is a promising energy harvesting approach which can be used not only in large-scale energy scavenging, but also in tiny-scale energy harvest. It is possible to address worldwide energy shortage and to promote personal electronics and self-powered systems by TENG [17]. 

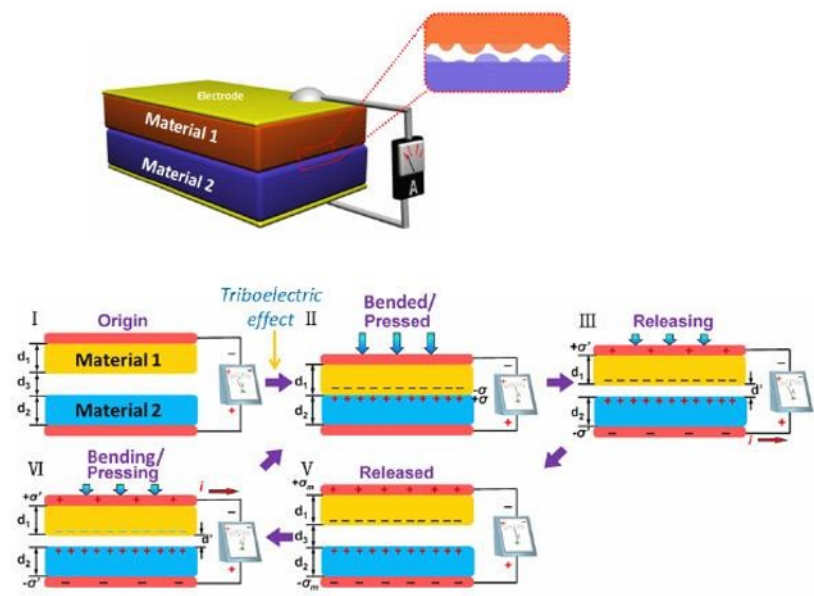

Figure 10: The working principle of triboelectric Nano-generator.

The advantages of triboelectric nanogenerator

(1) In a variety of energy harvesting devices, the ability of TENG to harvest human motion with high efficiency and large output power density has been proven. It has the features of high output voltage, environmental protection and safety [18]. (2) Compared with photoelectric and thermoelectric energy harvesting, the mechanical energy is almost independent of the weather and the working environment. (3) Because of its simple structure and large range of material selection, the entire device manufacturing process does not require expensive raw materials and advanced manufacturing equipment, which is conducive to large-scale industrial production. (4) The device is using flexible polymer film thin polymer as basic material. The device can be used for a long time since it is easy to process and easy to combine with other processing techniques [19]. So it is facile to be designed into textile cloths and to convert common cloth fabric into energy-storing devices will be better, thus reinforcing the combination with wearable products.

The status application of triboelectric nanogenerator to wearable device

1) Recently,Professor Dr Zhong Lin Wang led the research team to develop the nano-working mode, using vertical contactseparation mode composed of the PDMS film and aluminum foil to constitute a friction layer for triboelectric nanogenerator, which can be fixed in the clothes. As shown in Figure 12, the triboelectric nanogenerator can be converted into a sustainable power supply by collecting the vibrational energy and the kinetic energy of the human bod, which provides the basis for the self-powered power supply mode of wearable equipment [20]. (2) Chinese Academy of Sciences Institute of Nano-Research in the recent research has reported paper or textile batteries with the utilization of graphene, carbon nanotubes (CNT), or carbon Nano fiber cloth as the flexible substrate [21]. As shown in Figure 11, TENG cloth can be worn in many different regions of the body (for example, at the foot, under the arm and at the joint), and a self-charging power unit for smart electronics is developed to verify the viability of the whole wearable and self-charging power unit for future wearable smart electronics.

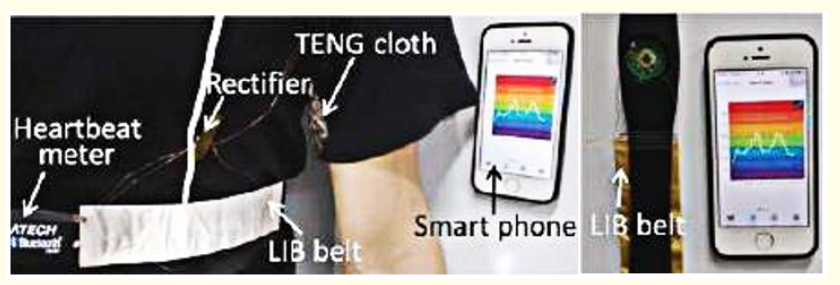

Figure 11: Optical image of integrated self-charging power system.

(3) A triboelectric nanogenerator (TENG) based on the contact-separation mode between a patterned polydimethylsiloxane (PDMS) film and an Al foil was fabricated between clothes for harvesting body motion energy. Under the general walking, the maximum output of voltage and current density are up to $17 \mathrm{~V}$ and $0.02 \mu \mathrm{A} / \mathrm{cm}^{2}$ respectively. As shown in Figure 12 , the TENG with a single layer size of $2 \mathrm{~cm} \times 7 \mathrm{~cm} \times 0.08 \mathrm{~cm}$ sticking on the clothes was demon strated as a sustainable power source that not only can directly light up 30 light-emitting diodes(LEDs), but also can charge a lithium ion battery by persistently clapping clothes [22]. The detection of bioactive chemicals in our body using the energy harvested from body motion is demonstrated.
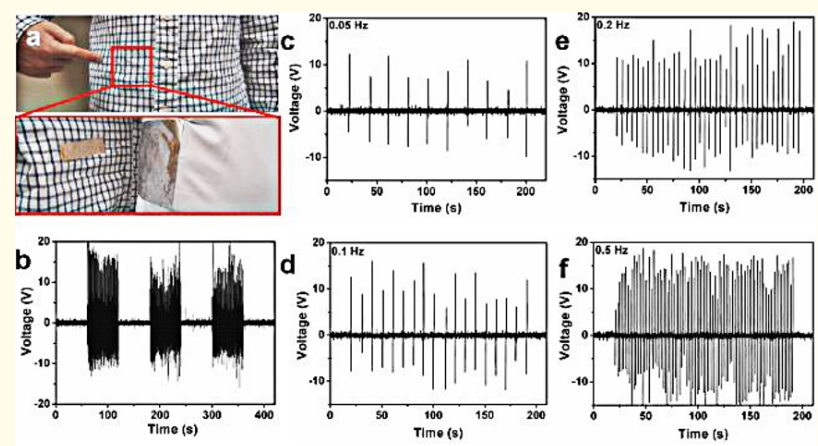

Figure 12: a) Photograph of a working TENG $(2 \mathrm{~cm} \times 7 \mathrm{~cm} \times 0.08$ $\mathrm{cm}$ in size) stuck on to the clothes with the shirt buttoned. (b)The output voltage of the TENG when walking. (c,d,e,f).The output voltage signals at different stride frequency, $0.05 \mathrm{~Hz}$ (c), $0.1 \mathrm{~Hz}$ (d), $0.2 \mathrm{~Hz}(\mathrm{e})$ and $0.5 \mathrm{~Hz}(\mathrm{f})$. 
Current problems of triboelectric nanogenerator in wearable applications

1. There are many problems such as low energy conversion efficiency, high output power, and unstable pulse electric signal in TENG.

2. Considering the requirements of wear ability, the lightweight, high flexibility, stretchable requirements and washable power supply for power generation devices are key challenges.

\section{Application design of friction nanogenerator}

According to the application principle of nanofriction generator, I put forward a design concept of intelligent night running clothes. The basic design principle is to make a human body motion energy collection and the storage into a one-dimensional fibrous structure device, making the clothing and nano device integrated into one, in order to achieve self-charging power supply system.

\section{Design Scheme}

The design method of the night running clothes is to use the friction plate to convert the body movement energy into power, collecting them in the flexible lithium-ion battery, and transmitting power through the integrated conductive wire throughout the garment.

Because there is more friction between the upper arm and the armpit when human body is running, the friction plates are placed at two sides of the garment. The lights are placed in the middle of the hat and the outside of the sleeves, the flexible lithium-ion battery is at the back, then distribute the integrated conductive wire in the clothing lining, connecting the friction plates, flexible batteries and light power into a fabric-based wearable self-charging supply system. As shown in Figure 13.

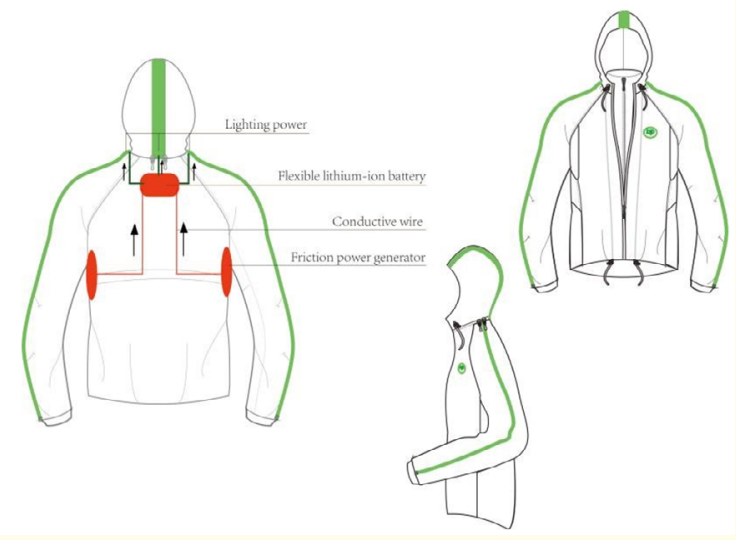

Figure 13: Circuit design.

\section{Design renderings}

The night running clothes is designed into double-placket look with drawstring on the hem to ensure the windproof effect when running. Using raglan sleeves so we can ensure that the upper arm has sufficient space for activity. The back of the garment is made of windproof fabric, separated from the lining which is made of mesh fabric in order to ensure the breathability of the back when exercising. The optical fiber ribbons located on the sleeve and the hat are assembled by zippers, which can be disassembled easily.The clothing effect diagram is shown in Figure 14.

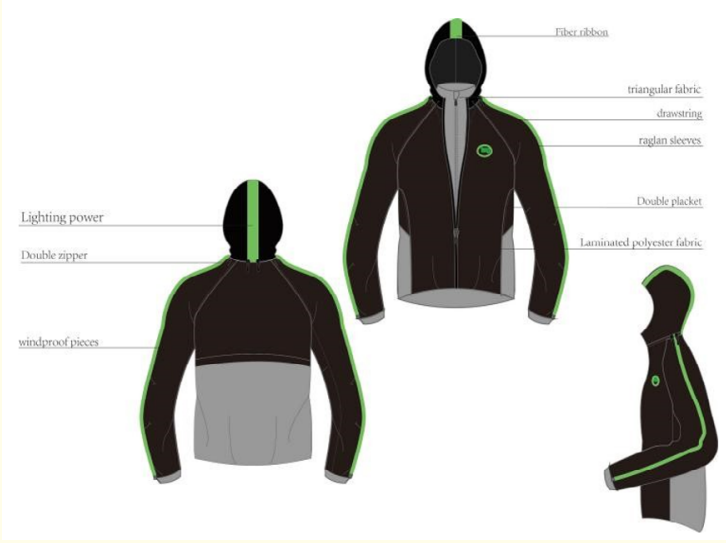

Figure 14: Effect drawing.

\section{Conclusion}

In order to effectively solve the problem of power supply for wearable devices, we can get various forms of waste energy from the surrounding environment. After years of development, researchers have more choices of materials, shape, structural design and the use of mixed devices into the study, therefore the output power and output stability of TENG are greatly improved. In the near future there is hope that it will be applied to the sustainable energy supply of wearable devices to achieve industrialization, greatly facilitating our daily life.

In this paper, by the comparison of piezoelectric nanogenerator and triboelectric nanogenerator,it is found that the fabric can be directly combined with the triboelectric nanogenerator for energy collection, and flexible power management circuit will be designed to realize a whole-flexible wearable self-charging power textile. Self-powered energy based on triboelectric nanogenerator will be a new direction for solving the problem of wearable equipment.

\section{Acknowledgments}

This work was partially supported by the Beijing Municipal Education Commission Project. 


\section{Bibliography}

1. GUO Yinben., et al. "Progress of the Research on Wearable Triboelectric Nanogenerator". Progress in Chinese materoals (2016): 91-100.

2. Xianming He. "The Research of Flexible Triboelectricity Nanogenerator Based on PDMS Composite Film". Chongqing University (2015).

3. Wang Z L and Wu W. "Nano-enabled energy harvesting for self-poweredmicro/nano-systems". Angewandte Chemie International Edition 51.47 (2012): 11700-11721.

4. Huangwei. "Research on the Prospect and Investment of Wearable Device". Lanzhou University (2015).

5. Dong F L. "Research on the industry chain and trend in development of industry of wearable device". Guangdong Academy of Social Sciences (2015).

6. Shuntian FENG. "The present situation and trend of wearable equipment". Information and Communication Technology 03 (2014): 52-57.

7. Yi G., et al. "The Present Situation and Prospect of Wearable Equipment". Electronic Science and Technology (02) (2014): 238-245.

8. Wikipedia [EB/OL] (2014).

9. Feng ST. "The present situation and trend of wearable equipment". Information and Communication Technology (2014): 52-57.

10. Business Insurance. Wearable Devices' Risks Emerge 48.19 (2014).

11. Song BL. "Overview of the current situation and future development of wearable equipment". Silicon Valley (2014): 9-10.

12. Starner T. "Human-powered wearable computing". IBM Systems Journal 35. (3/4) (1996): 618-629.

13. ZL Wang. Adv. Mater. 24 (2012): 4632 . b) ZL. Wang, ACS Nano (2013): 9533.

14. uX., et al. "A self-charging power unit by integration of a textile triboelectric nanogenerator and a flexible lithium-ion battery for wearable electronics". Advanced Materials 27.15 (2015): $2472-2478$.

15. Z L Wang. "The principle and Potential Application of Piezoelectric Nano-generator". Physical 11 (2006): 897-903.
16. ZL Wang. "The Principle and Potential Application of Piezoelectric Nano-generator. b) Guo Y B, Zhang Q H., Li Y G, Wang H Z. "Progress of the Research on Wearable Triboelectric Nanogenerator". Materials China (2016):91-100-127

17. Zheng Z SHAO. "Study on One-Dimensional Zn O Nanostructures Based Piezoelectric Nanogenerator". National University of Défense Science and Technology (2010).

18. Zang Y., et al. Materials Horizons 2.2 (2015): 140-156.

19. Yang Y and Wang L Y. "Composite electromagnetic - triboelectric nanogenerator”. Chinese Science Bulletin (2016):12681277.

20. Xu S., et al. "Self-powered nanowire devices". Nature Nanotechnology 5 (2010): 366-373.

21. Sun Jing. "Fabrication and Performance of Triboelectric Generator Based on Biocompatible Materials". Tianjin University of Technology (2015).

22. Wu J., et al. Chemical Reviews 115.7 (2015): 2559-2595.

\section{Volume 2 Issue 9 September 2019}

(C) All rights are reserved by Jing-Yan Yu and Li Liu. 